\title{
On the Phase Diagram of the $\mathrm{Cr}-\mathrm{O}$ System at High Pressure of Oxygen and Some Properties of the Compound $\mathrm{CrO}_{2}+\mathrm{X}$
}

\author{
Yasumasa Goto and Toshio Kitamura*
}

The pressure versus temperature diagram of the chromium oxides $\left(\mathrm{Cr}_{2} \mathrm{O}_{5}, \mathrm{CrO}_{2}\right.$ and $\left.\mathrm{Cr}_{2} \mathrm{O}_{8}\right)$ was determined by the closed vessel method in the range of higher oxygen pressures up to 600 atms. Chromium pentaoxide $\mathrm{Cr}_{2} \mathrm{O}_{5}$ is comparatively stable below $200^{\circ} \mathrm{C}$, but it dissociates into $\mathrm{CrO}_{2}$ above this temperature. The stable ranges of $\mathrm{CrO}_{2}$ and $\mathrm{Cr}_{2} \mathrm{O}_{3}$ in the diagram are separated by the dissociation pressure curve of $\mathrm{CrO}_{2}$ which rises exponentially with increasing temperature through the points $\left(450^{\circ}, 100\right.$ atms.) and $\left(520^{\circ} \mathrm{C}, 600 \mathrm{atms}\right.$.). The presence of $\mathrm{Cr}_{3} \mathrm{O}_{8}$, which had been reported to be stable at room temperature, was not confirmed above $200^{\circ} \mathrm{C}$ in the present experiments. The results of determination of oxygen contents in $\mathrm{CrO}_{2}$ phase indicate that this phase is non-stoichiometric; their composition varies from $\mathrm{CrO}_{1.80}$ to $\mathrm{CrO}_{2.02}$ depending on the equilibrium conditions. The ratio of $\mathrm{O} / \mathrm{Cr}$ increases with the fall of temperature and incresing oxygen ' pressure. The lattice constants of $\mathrm{CrO}_{2+\mathrm{x}}$ (rutile type structure) decrease with increasing oxygen contents. The latter effect is quite consistent when we assume that the excess $\mathrm{Cr}$ ion are present as interstitials at the interlattice points of oxygen. The accurate lattice constants of stoichiometric compound $\mathrm{CrO}_{2}$ are found to be $\mathrm{a}=4.408, \mathrm{c}=2.910$ a.u., $\mathrm{a} / \mathrm{c}=1.51$. The saturation magnetization of $\mathrm{CrO}_{2+\mathrm{x}}$ at room temperature seems to increase with increasing $\mathrm{O} / \mathrm{Cr}$ ratio. The ferromagnetic Curie point of them, however, seems not to change with $\mathrm{O} / \mathrm{Cr}$ ratio by more than $10^{\circ} \mathrm{C}$. (Received April 20, 1962)

\section{Introduction}

Recently chromium dioxide $\mathrm{CrO}_{2}$ was found to be ferromagnetic, and much interest is directed toward its mechanism. The compound was first synthesized by Wöhler ${ }^{1)}$ and the matgnetic properties has been investigated by Guillaud et $a 1^{2}$. Oxides having higher $\mathrm{O} / \mathrm{Cr}$ ratios than $3 / 2$ are never obtained by means of the calcination of metallic chromitum at atmosphric pressure. However, it was found that $\mathrm{CrO}_{2}$ could be prepared when metallic chromium or chromic anhydrate was heated under higher pressure of oxygen. In these connections, the determinations of the accurate dissociation pressure of oxygen of these oxides at various temperatures are required.

Now these pure oxides are actually prepared in various methods ${ }^{4}$, but the systematic studies of the chemical equilibrium among these oxides have not yet been made. Furthermore, the ratios $\mathrm{O} / \mathrm{Cr}$ of the $\mathrm{CrO}_{2}$ phase, and therefore their physical properties, are supposed to be dependent largely on the equilibrium conditions under which the oxides are prepared. In the present works, these points have been dealt with in details.

\section{Experimental Procedure}

When chromic trioxide $\mathrm{CrO}_{3}$ is heated in a closed vessel, it dissociates into lower oxides through the process as follows; $\mathrm{CrO}_{3} \rightarrow \mathrm{Cr}_{3} \mathrm{O}_{3} \rightarrow \mathrm{Cr}_{2} \mathrm{O}_{5} \rightarrow \mathrm{CrO}_{2} \rightarrow \mathrm{Cr}_{2} \mathrm{O}_{3}$. Therefore, the pressure of

* Laboratory of Metallurgy, Faculty of Science, Kyoto University 
oxygen developed by the dissociation may be calculated from the confirmation of the species of end products, under the assumption of non-leakage of evolved oxygen from the vessel. The latter condition were secured by the attentive use of packing material. Accurately weighed chromium trioxide of Merk were closed in the vessel such as depicted in Fig. 1. The body of it was made of 18-8-stainless steel and aluminium foils were used for packing material which prevented the escape of oxygen gas. The vessel was designed so as to be used even for 1200 atms of pressure at $600^{\circ} \mathrm{C}$. After keeping the vessels at required temperature for 5-200 hours until the equilibrium state were attained, and then the vessel were quenched into ice water. The pressure of evolved oxygen were calulated by detecting the species of end products and the initial amount of packed $\mathrm{CrO}_{s}$. Geiger "counter spectrometer was used for identification of end products using $\mathrm{Cu} \cdot \mathrm{K}_{\alpha}$ radiation.

Analysis of oxygen content in $\mathrm{CrO}_{2+\mathrm{x}}$ were carried out by the measurement of

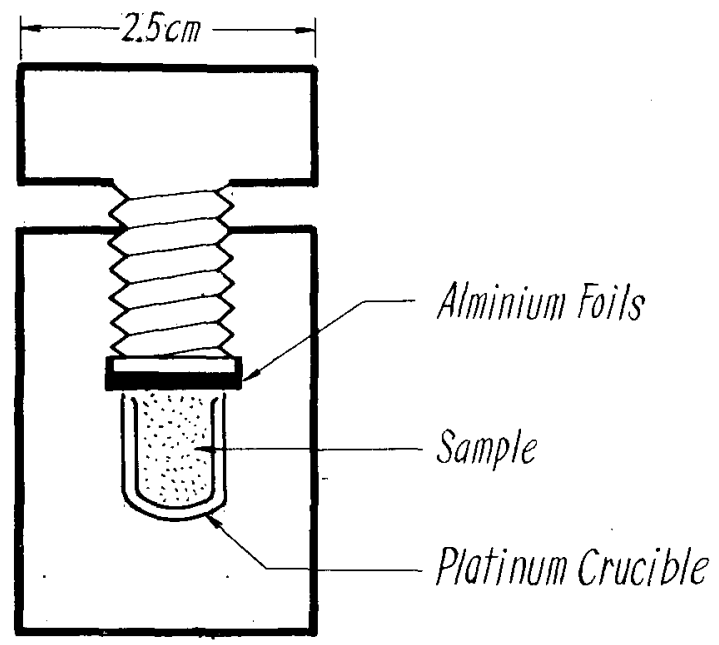

Fig. 1 The gas-tight reaction vessel made of 18-8. Cr stainless steel.

the weight loss during the calcination at $800^{\circ} \mathrm{C}$ for 30 minutes in air : by the latter treatment $\mathrm{CrO}_{2}$ dissociates into stoichiometric chromium sesquioxide ${ }^{5)}$. The accuracy of the results are believed to be within $\pm 0.3 \%$. Lattice constants of $\mathrm{CrO}_{2+\mathrm{x}}$ specimens were accurately determined for each compositions.

\section{Results and Discussion}

(1) The P-T Diagram of the Cr-O System at High Pressure of Oxygen and Some Ther. modynamical Considerations.

The results of $\mathrm{X}$-ray analyses for the oxides obtained at various temperatures and oxygen pressures are summarized in Fig. 2. The presence of three compounds $\mathrm{Cr}_{2} \mathrm{O}_{5}, \mathrm{CrO}_{2}$ and $\mathrm{Cr}_{2} \mathrm{O}_{3}$ are identified at these experimental conditions. The stable range of these oxides are separated by two boundary lines. The neighbouring phases coexist on these lines. The rates below $200^{\circ} \mathrm{C}$ were so slow that the boundary line between $\mathrm{Cr}_{2} \mathrm{O}_{5}$ and $\mathrm{CrO}_{2}$ phase could not be determined so accurately. Inasmuch as the com. pound $\mathrm{Cr}_{2} \mathrm{O}_{5}$ did not undergo a dissociation into $\mathrm{CrO}_{2}$ below $200^{\circ} \mathrm{C}$ within 200 hours, there may be some ambiguity in the dissociation curve of $\mathrm{Cr}_{2} \mathrm{O}_{5}$ denoted by broken line.

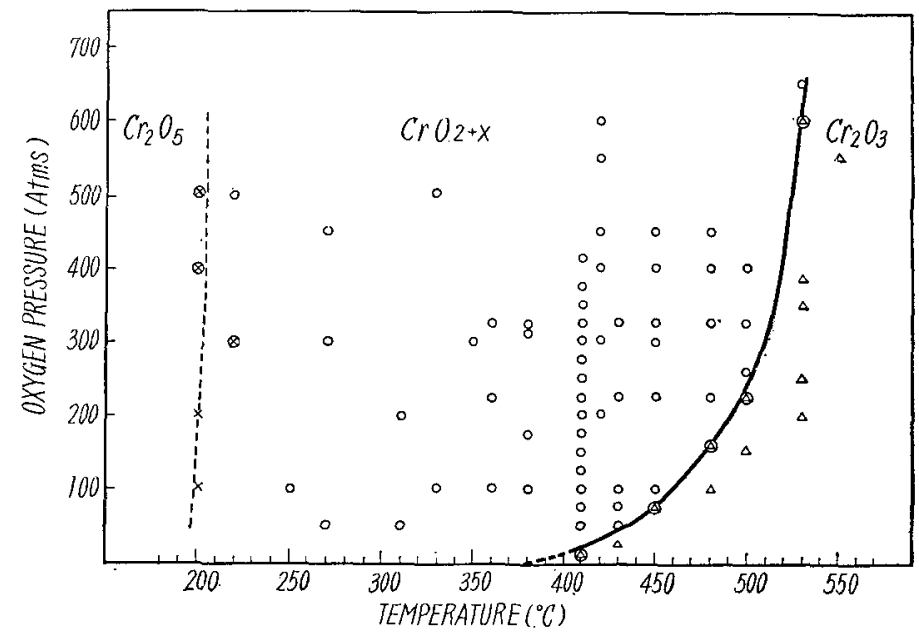

Fig. 2 Phase equilibrium of chromium oxides in oxygen pressure versus temperature diagram. 
The oxides having higher oxygen content than $\mathrm{Cr}_{2} \mathrm{O}_{5}$ were not obtained as stable forms in the present experiments. The compound $\mathrm{Cr}_{3} \mathrm{O}_{8}$ are likely to be stable at the lower temperature, but not certain.

Kubota $^{6)}$ reported a similar diagram for this system with somewhat differences from the present data, especially concerning with the phase boundary between $\mathrm{Cr}_{2} \mathrm{O}_{5}$ and $\mathrm{CrO}_{2}$. As a conceivable origin of the difference there may be a experimental errors caused by the leakage of evolved oxygen during experiments. In this connection, some thermodynamical considerations are given as follows. The changes in free energy $\Delta \mathrm{F}$ and heat of reaction $\Delta \mathrm{H}$ of the reaction

$$
\mathrm{CrO}_{2} \rightarrow \frac{1}{2} \mathrm{Cr}_{2} \mathrm{O}_{3}+\frac{1}{4} \mathrm{O}_{2}
$$

are calculated using the P-T curve of the present study shown in Fig. 2 with the aid of two equation (1) and (2).

$$
\begin{aligned}
& \Delta \mathrm{F}=-\mathrm{RT} \ln \mathrm{Po}_{2} \\
& \Delta \mathrm{H}=\mathrm{RT} \mathrm{dln} \mathrm{Po}_{2} / \mathrm{dT}
\end{aligned}
$$

where $\mathrm{R}$ is gas constant, $\mathrm{T}$ is absolute temperature and $\mathrm{Po}_{2}$ is pressure of oxygen. The plot of the values of $\operatorname{lnP}$ as a function of the reciprocal of temperature gives a straight line as practically shown in Fig. 3. The free energy change and the heat of reaction are respectively given as

$$
\begin{aligned}
& \Delta \mathrm{F}=-1.2 \mathrm{Kcal} / \mathrm{mol} \cdot \mathrm{CrO}_{2} \\
& \Delta \mathrm{H}=6.6 \mathrm{Kcal} / \mathrm{mol} \cdot \mathrm{CrO}_{2}
\end{aligned}
$$

On the other hand the heat of reaction $\Delta \mathrm{H}$ was directly estimated from the specific heat measurement. Fig. 4 shows the specific heat versus tem. perature curve of $\mathrm{CrO}_{2}$. The chromium dioxide begins to decompose at about $560^{\circ} \mathrm{C}$ at this heating condition in air. Graphical integration of specific curve gives the value of the heat of reaction, i.e., the shaded area of figure. The above mentioned values which was estimated from the $\mathrm{P}-\mathrm{T}$ diagram may be said to be fairly in good agreement with these values in order, when considering the accuracy of the experiment of this sort.

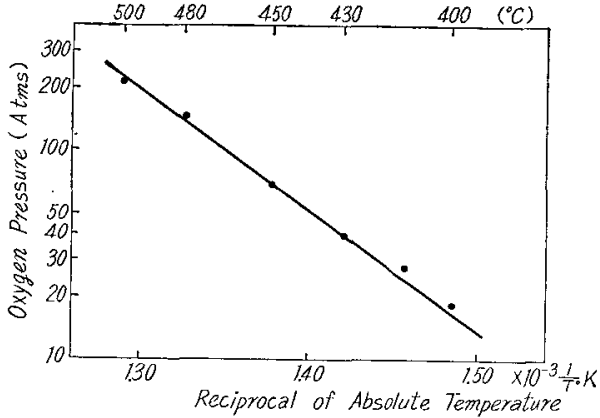

Fig. 3 The $1 \mathrm{nP}-1 / \mathrm{T}$ relation for the dissociation pressure of oxygen of $\mathrm{CrO}_{2}$.

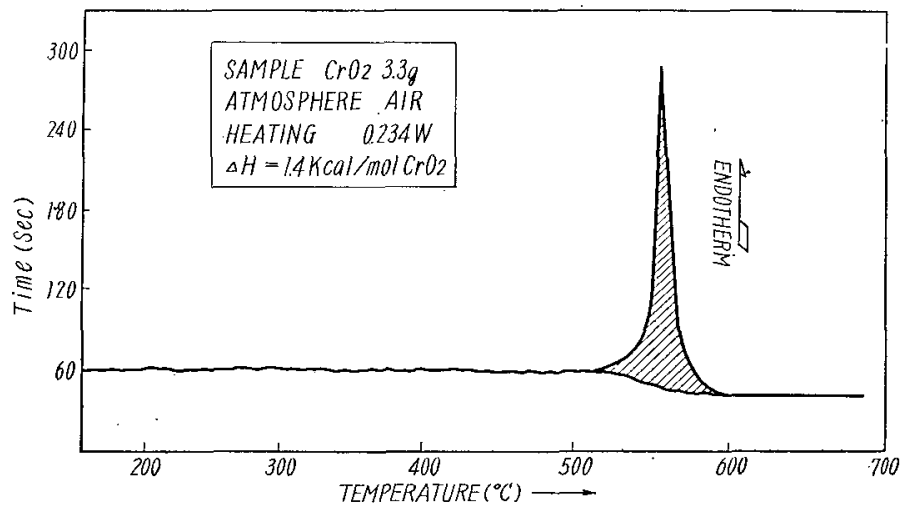

Fig. 4 The result of heat measurement. Vertical axis expresses the time required for arising the temperature of specimens and Pt crucible by $2^{\circ} \mathrm{C}$. 
(2) The Nonstoichiometry of $\mathrm{CrO}_{2+\mathrm{x}}$

The deviation of oxygen contents from stoichiometric composition in $\mathrm{CrO}_{2}$ phase were determined by the measurement of the weight loss during the reduction of the specimens into $\mathrm{Cr}_{2} \mathrm{O}_{3}$, in relation to equilibrium condition. The results are shown in Fig. 5. The deviation $\mathrm{x}$ increases with both increasing oxygen pressure and decreasing temperature, extending from -0.10 to 0.02 . Fig. 6 shows the variation of the lattice constants with $x$. Both of the parameter $a$ and $c$ decrease with increasing amount of oxygen. It may be indicated that such a change of lattice parameter is not due to the oxygen interstitials but to the cation vacancies. Similarly in the samples of the lower contents than stoichiometry, $\mathrm{Cr}$ ion are supposed to occupy the interstitices of oxygen frame work.

The $a / c$ ratio of the parameter slightly decreases as the oxygen ratio becomes higher. Accurately measured lattice constants of the stoichiometric $\mathrm{CrO}_{2}$ are found to be

$$
\begin{aligned}
& a=4.408 \pm 0 \cdot 004 a . u ., \\
& c=2.910 \pm 0.004 a . u ., \\
& a / c=1.51
\end{aligned}
$$

(3) Saturation Magnetization of the Compound $\mathrm{CrO}_{2+\mathrm{x}}$

The mechanism of ferromagnetism has been discussed by many investigator and explained by considering cation-anion-cation superexchange interaction. The Bohr magneton number per $\mathrm{Cr}$ ion was reported to be $2.07^{3)}$ or 2.016).

The temperature dependency of electrical resistivity of $\mathrm{CrO}_{2+\mathbf{x}}$ was measured by $\mathrm{Kubota}^{7}$. And it became clear that the compound is semiconductive and the resistivity at room temperature extends from 0.1 to 1.0 $\mathrm{ohm} \cdot \mathrm{cm}$, showing no dependence on the $\mathrm{O} / \mathrm{Cr}$ ratio.

Although the nonstoichiometry of the compound would probably affect the magnetic and electrical properties, they have not measured precisely owing to the difficulties in sample preparations. In the present experiments the saturation magnetization was measured as a function of oxygen contents at room temperature. The results are shown in Fig. 7. Measurements were made using the magnetic tortion bala-

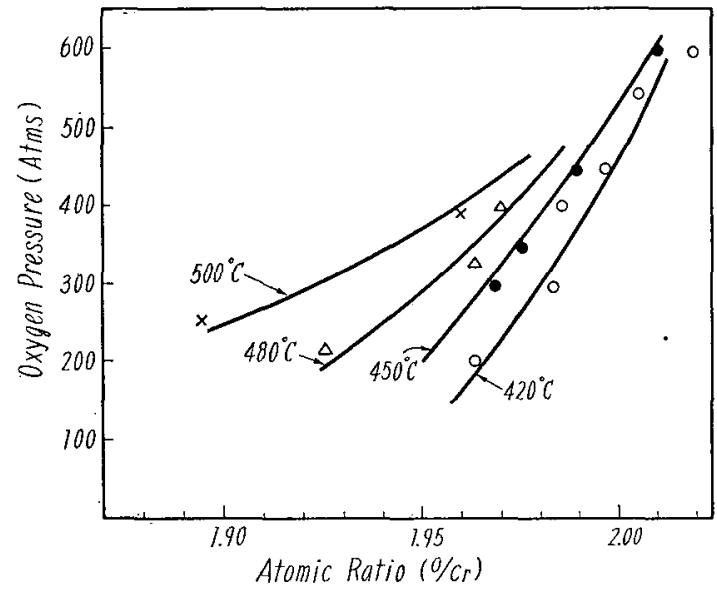

Fig 5. The difference in $\mathrm{O} / \mathrm{Cr}$ ratios of $\mathrm{CrO}_{2}$ phase at several equilibrium conditions.

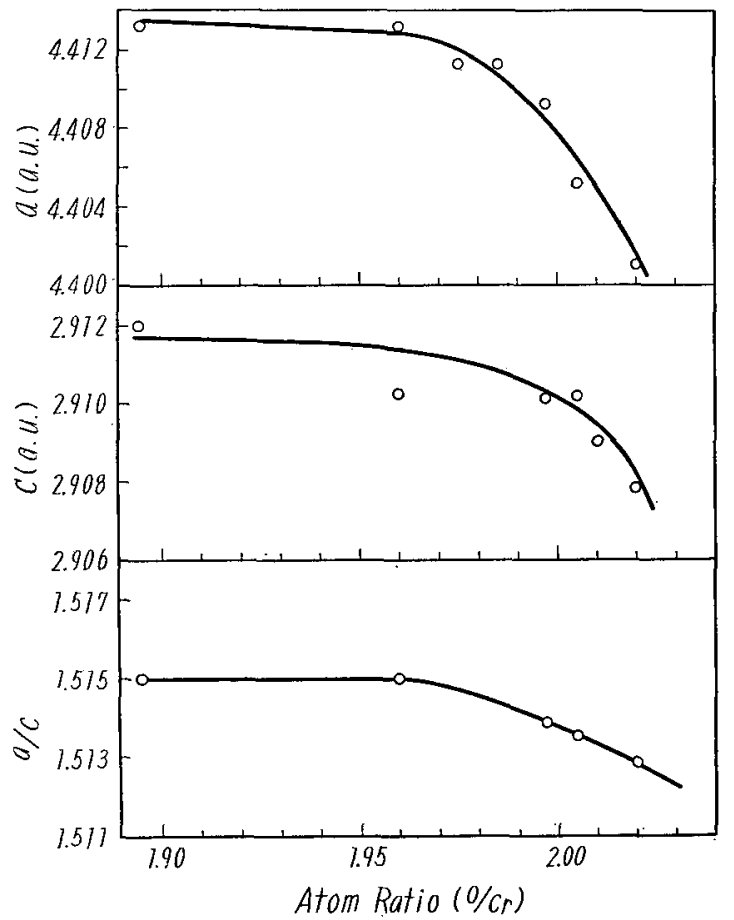

Fig. 6 The variation of the lattice constants as a function of atomic ratio in $\mathrm{CrO}_{2+x}$ phase. 
nce improved by Mekata and Takaki ${ }^{8}$. The saturation magnetization seems to increase with increasing $\mathrm{O} / \mathrm{Cr}$ ratio. In the specimens containing excess $\mathrm{Cr}$ ion over stoichiometry, chromium ion would occupy the tetragonal face center of rutile structure probably as $\mathrm{Cr}^{8+}$ ion, reducing therefore the superexchange interaction. The ferromagnetic Curie temperature did not differ so much as could be detected.

\section{Results}

(1) The pressure versus temperature diagram of the $\mathrm{Cr}-\mathrm{O}$ system was determined at high oxgen pressure as shown in Fig. 2.

(2) The solid phase of rutile structure is nonstoichiometric, whose $\mathrm{O} / \mathrm{Cr}$ ratio extends from 1.90 to 2.02 .

(3) The lattice constants a and c of the rutile type compound $\mathrm{CrO}_{2+\mathrm{X}}$ both decrease with increasing

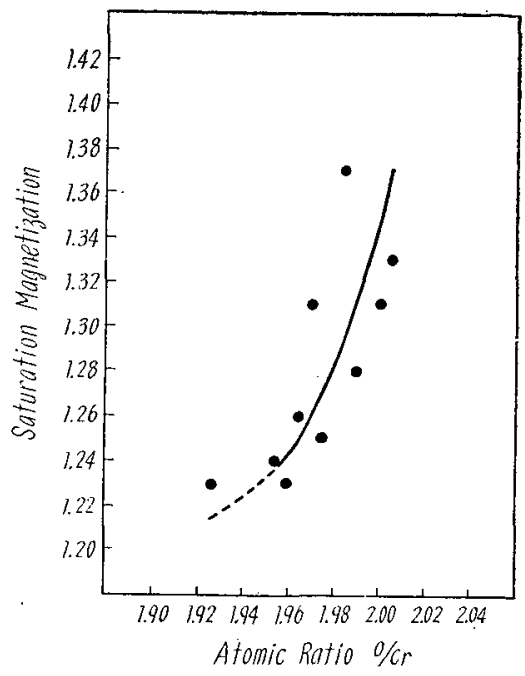

Fig. 7 Change in saturation magnetization at room temperature of $\mathrm{CrO}_{2+x}$ for various oxygen contents. $\mathrm{x}$ values.

(4) The saturation magnetization at room temperature of the compounnd $\mathrm{CrO}_{2-\mathrm{T}}$ seems to increase with increasing $\mathrm{x}$ values.

\section{Acknowledgement}

The writers would like to acknowledge the helpful suggestions and criticisms of Professor S. Kachi and Dr. T. Takada in Kyoto University. Thanks also are due to Dr. M. Mekata for his advices during magnetic measurements.

\section{Literature}

1) (a) K. Siratori and S. Iida: J. Phys. Soc. Japan 15 (1960), 210

(b) J. B. Goodenough: Phys. Rev. 117 (1960), 1442

2) F. Wöhler : Gött. Nachr. (1859), 147

3) C. Guillaud, A. Michel, J. Bernard and M. Fallot: Compt. Rend. 219 (1944); 58

4) (a) S. M. Aruya, S. Skares and B. Glusikowa: Zhur. Obshei Khimi. 23 (1953), 1241

(b) O. Haushild: J. Amer. Chem. Soc. 74 (1952), 1676

(c) B. T. Thamer: J. Amer. Chem. Soc. 79 (1957), 574

5) A. Michel and J. Bernard: Bull. Soc. Chim. 10 (1943), 315

6) B. Kubota: J. Phys. Soc. Japan 15 (1960), 1706

7) B. Kubota: J. Phys. Soc. Japan 16 (1961), 345

8) M. Mekata and H. Takaki: Kinzoku Butsuri (Metal Phys), 7 (1960), 126 